\title{
Creating Legal Awareness through Information Communication Technology for Development (ICT4D) Project in Bangladesh: A Case Study
}

\author{
Dr. Md. Mahfuz Ashraf \\ Department of Management Information Systems \\ University of Dhaka, Dhaka-1000, Bangladesh \\ Email: ashraf.mahfuz@gmail.com \\ Md. Rakibul Hoque \\ School of Management \\ Huazhong University of Science and Technology, Wuhan, 430074, China. \\ Email: rakibulmisdu@gmail.com \\ Bushra Tahseen Malik \\ Brainstorm Bangladesh, Dhaka 1213, Bangladesh \\ Email: bushra@brainstorm-bd.com
}

\begin{abstract}
Billion-billion dollar spends for the implementation of Information Technology (IT) in rural/village areas of developing countries through the direct-indirect interventions of The United Nations (UN), the World Bank and the International Telecommunication Union (ITU) and so on. Unfortunately, focus has been given to the supply side (implementation) of the interventions than understanding the demand (impact) towards socio-economic progress of the beneficiaries. Further, how far such interventions address socio-economic progress or developmental challenges at the grass root level remains questionable. This article aimed to address this challenge by focusing a case study of a multi-purpose community access center in a village area of a developing country; Bangladesh. This research finding, based on the participants' perceptions, attitude and experiences towards IT and socio-economic progress (Legal awareness). We found that the participants faced gender discrimination during the implementation of IT knowledge in their real World. Towards this IT enabled legal awareness in rural areas, NGOs with their social welfare oriented projects has a very concerned role to play.
\end{abstract}

Keywords: Multi-purpose community access center, Bangladesh, village, Information Technology (IT), DigitalDivide.

\section{Introduction}

Bangladesh is one of the most densely populated countries in the World. The majority of the population (76\%) lives in village areas where unemployment, literacy and poverty have not been improved since the independence of the country in $1971 .^{1}$ The rate of literacy here is now $54.8 \%$, with $40 \%$ of its people living below the poverty line. ${ }^{2}$ Poverty strikes unevenly among village groups and the large section of population living in extreme poverty due to illiteracy, ill health, lack of access to basic services such as education, legal support, powerlessness, social and physical isolation, vulnerability and unemployment. Amongst the number of causes, lack of access to legal support is one of the main causes that the nation has been addressing to improve the socio-economic status of the villagers with the direct-indirect interventions of Non-Government Organizations (NGO), international donor agencies and development partners of Bangladesh. In rural Bangladesh, legal support and practices have not reached every sphere of the community, especially those containing the poor and under-privileged.

From a general point of view legal rural support comes to the people from two distinguished sources. Here the first one is the government itself, which has 
been constitutionally bound to provide with legal services to all its citizens. In Bangladesh Ministry of Social welfare has got a cell in every District Judicial Magistrates court to assist poor people in his/her legal approaches, free of cost. Local government agencies like Union Parishad is also supposed to litigate the disputes among the rural people, in a sense it also can be taken as a legal assistance as, it saves time, money and effort of both the accused and accuser. Along with this traditional legislative councils are carried out in villages such as 'Panchayeta', 'Darbar' etc.

But functional inefficiency, lack of transparency and accountability arise as hinders to the proper availability of these services to their true receivers. In case of traditional legislative councils, class and religious bias, have also proved this system somewhat malfunctioned.

Another source of rural legal support available in Bangladesh is the third sector as known as the NonGovernment Organization (NGO) sector. Like, The Bangladesh Legal Aid and Services Trust (BLAST) which is a large-scale national organization focusing exclusively on the mobilization of legal resources for women, the poor, and other marginalized groups. Another prominent organization in this sector is BRAC. It is a holistic organization which tackles poverty on multiple fronts, being the world's largest NGO, It operates a modest legal empowerment program at the micro level in Bangladesh. ${ }^{3}$ Here it stands, The Madaripur Legal Aid Association (MLAA) that focuses solely on mobilizing legal resources on a regional scale. MLAA operates offices in three neighboring districts and operates at the meso and micro levels of intervention and has recently embarked on macro level advocacy work. Activities of Nagorik Uddyog (NU) is also worth to be noted as, NU is a small NGO with 45 staff members working in four district offices with an additional head office in Dhaka. NU operates at the meso and micro levels.

Beside these kinds of stereotyped legal assistance in rural society, there is another form of informality and externality goes hand to hand. As a land reform processes in Bangladesh has been assessed, looking in particular at peasants' aspirations for land and the extent to which legal aid has been made available at the local level. But the illustration shows that legal aid has been critical to the struggle of landless peasants for land. Here, even though legal assistance did not enable the peasants to break the power of landowners, it did help to restrain the latter in some cases. It also indicates that social mobilization by non-governmental organizations, peasants' organizations and professional organizations has been more decisive than the supply of legal aid. ${ }^{4}$

This article focuses such a particular interventions, namely 'Gonokendra', (meaning multi-purpose community access center) aiming to build a learning society which conducive to bridging so-called 'digitaldivide' in village areas of Bangladesh. The description of the case study is followed by some key findings related to the participants' socio-economic progress or development from their own perceptions, attitudes and experiences. Though NGOs and development partners are actively promoting legal support in rural areas, the lack of understanding, of awareness and of participation have been identified as key factors to be overcome in seeing grassroots development.

\section{Setting the Scenario}

In 1995, the Bangladesh Rural Advancement Committee (BRAC) introduced community-based village libraries known as 'Gonokendra' under the BRAC Education Program (BEP) and Continuing Education Programme (CEP) in rural areas of Bangladesh. ${ }^{1}$ The primary objective of the Gonokendra was to create access to printed reading materials and other continuing education to rural neo-literate, semiliterate, literate communities, and to stimulate interest in acquiring information and encountering new ideas. It was argued that this would create an environment that is conducive to a 'Learning Society'. ${ }^{3}$ Since 1999, Gonokendra has introduced new Information Technology (IT) programs and renamed the intervention from community based village library to multi-purpose community access center. ${ }^{3}$

\subsection{New initiative in Gonokendra: IT program}

To encourage adolescents, youth, females, poor and adults to become familiar with computer and its various applications in village areas, BRAC initiated an Information Technology (IT) program in Gonokendra in late $1999 .^{5}$ The objectives of the IT program are: ${ }^{6}$

- to increase familiarity with computers in rural communities,

- to promote computer training in rural areas,

- to create access to IT education (CDs covering basic Health, Mathematics and English 
language topics) for rural adolescents, youth and adults,

- to expose rural people to new and modern technology (computer) and develop skills and capacity of librarians, adolescents, youth, general villagers to face future challenges,

- to give special attention to poor women, girls and disabled villagers. BRAC fully or partially subsidizes training fees for these groups.

The proposed outcome of this program is to ensure rural communities have increased access to a range of top quality, financially sustainable continuing IT-based education services. ${ }^{7}$ Some of these IT services are described below:

\section{Computer Training Program}

Computer training is a component of the IT program offered by Gonokendra. It consists of different computer courses for various age groups in village areas depending on the duration and capacity of the trainer who is the Gonokendra's librarian. Each librarian has the role of trainer for all computer courses offered in the Gonokendra. ${ }^{7}$ The librarian is trained at BRAC's TARC (Training and Resource Center) in the city. After successfully completing an initial 12 day training session at TARC, a librarian then returns to her Gonokendra and initiates computer courses as the instructor. $^{7}$

\section{Multi-media Based Information Dissemination Program}

Each Gonokendra has a set of 15 to 20 CDs containing different educational and social awareness issues, including general knowledge, health/legal information, subject rhymes and games. This provides a valuable information bank for the villagers. ${ }^{8}$ The villagers attend multi-media session in a group once or twice in a week. Further, one can come alone to watch the CDs at Gonokendra depending on the availability of the computer.

\section{Research Objective and Question}

The ultimate research objective of this research is to understand the processes of the adaptation and implementation of ICT-based initiatives towards development in a given society like Bangladesh. The results of this research can be applied to a range of cases for testing and validation purpose. In order to achieve the main objective, this research will try to seek the answers from the following broad research question:

How and in what context can ICT create legal awareness in rural areas of Bangladesh?

The research question will explore the role and actions of various actors during the process of adaptation and implementation of ICT based project in rural areas of Bangladesh.

\section{Research Methodology}

This research follows an interpretive approach through a case study method. An interpretive approach, using qualitative methodologies gives this research scope to address issues of ICT's influence and impact on development, and assists us in understanding processes, as interpretive research lends itself to investigation of complex human processes within their social context. ${ }^{9,10}$ The aim of the data collection was to gather information to answer the research question. A flexible research instrument was designed to enable us to ask questions that could capture the perspectives of participants and respondents within their settings. ${ }^{11,12}$

We applied a purposive sampling procedure to select the information communication technology for development (ICT4D) projects, villages where the projects operated. This study provides results from one Gonokendra as part of a large field trip undertaken from September to December 2006 at three Gonokendras located in three different villages of Bangladesh. Respondents included the operator/trainer (in-charge of operations), users, government officials, and other villagers who were aware of the ICT4D project. The sample size was not pre-determined and data was gathered from the above categories and from local secondary sources (official records, reports and statistics from the local public offices) during the one month stay in each village. Together these sources formed a rich data set.

Data collection techniques included in-depth interviews, focus group discussions (FGD), and observations. The discussions during the interviews and FGDs centred on the ICT4D projects and their influence and effects on the socio-economic and socio-cultural development, as well as the effectiveness of the ICT programs and views on facilities offered.

Interviews were voice-recorded in the local language and translated into English by the research team. Thematic analysis ${ }^{13}$ was used for field data analysis and 
this activity assisted us to identify the issues or themes that emerged from interview transcripts. Until recently, qualitative researchers were not very explicit about how they went about assigning units of meaning to their data $^{14}$. We followed the method of doing this as proposed by Miles \& Huberman ${ }^{14}$ : "the conventional advice was to go through transcripts or field notes with a pencil, marking off units that cohered because they dealt with the same topic and then dividing them into topics and subtopics at different levels of analysis”. In this method it is expected that topics (themes) or subtopics (sub-themes) recur with some regularity; so, finally, themes or sub-themes are given names. The following four steps show how we identified or discovered issue/themes from the interview transcripts:

a) Highlighted and identified meanings of sentences or paragraphs (in transcripts) that we felt relevant and important to the research objectives/questions;

b) Put a label on each identified meaning within sentences and placed labels on the tables;

c) Grouped relevant labels in order to discover sub-themes;

d) Grouped sub-themes in order to establish overall themes.

The entire process followed an iterative cycle, the intention being that themes from one study site would guide us to explore similar or new themes in other studies; this was achieved and themes were established. Following ${ }^{15}$, we avoid 'generalisations' and give a clear description of the context along with the interpretation in our case study before introducing the theme statements for each study site, thereby facilitating 'particularisation'.

In this paper we describe particular case studies and interpret the participants' experiences. Taking this approach to our research produced unique knowledge within a particular context. The quality of research was enhanced through the following measures:

- Triangulation through the various datacollection techniques and data sources for our research, which increased the data validity and reliability and reduced the risk of bias;

- A wide spectrum of perspectives was obtained by in-depth interviews, focus group discussions, observations and document reviews involving different participating groups. This enabled us to obtain interpretations from different participants, as proposed by Benbasat et al. ${ }^{16}$

- We followed Klein and Myers ${ }^{17}$ as a guide to principles for conducting and evaluating interpretive field study research.

\section{Findings from the Study Site: Awareness of Legal Issues}

The findings are based on the participants' perceptions, attitudes and experiences of Gonokendra's activities and its relevance with their socio-economic progress or development from their own perspectives. The findings are now presented for each category of interviewee in the Gonokendra. These include the librarian/trainer, trainees, general rural people (who aware about the activities of Gonokendra in their village) and trainees' guardians.

The Gonokendra multimedia sessions disseminate legal information that villagers can act upon; such as the prohibition of child marriage, of dowry in marriage, and of participation in salish (village arbitration), mostly by the poor. Here we discuss some of the legal issues that the participants consider positive in their development.

\subsection{Prohibition of Child/Early Marriage}

According to law, child marriage (i.e., below 18) is prohibited in Bangladesh, but it is still widely exercised throughout the country, especially in remote rural areas. Our participants in the Gonokendra villages tell us child/early marriage is commonly practiced: it was a social custom for people to get married as children. They say that poverty the main reason, because of the expense associated with keeping daughters at home. The consequences of child or early marriage are bad, leading to outcomes like some described by one of our participants:

"I married my wife when she was only 15 . I feel really sad that our marriage was a route of much suffering, for she was the mother of two children by the age of 17. (Male FGD 5_Vill 2)”

In general, early marriage happens among the poor. It is not good for the young mother's health; they catch different diseases and become physically weak. As the husbands are too immature to head a family, frequent marriage failure or abandonment of their partners are common. (Female FGD 5_Vill 1)

The participants stress the importance of understanding the consequences of child/early marriage 
as learned from Gonokendra multimedia sessions so that they become aware of the necessity of their society's stopping the practice (see Vignette 1). One woman told us:

When a woman is married early, she cannot know how to plan her family. As a result, the couple will have too many children. Gonokendra's librarian/trainer told us in the multimedia sessions about the harmful consequences of child marriage. We know that there is a certain age limit for marriage which has been decreed by law. Our librarian/trainer apa (madam) persuaded us to maintain this legal age, which I have followed; hence my eldest daughter's marriage in last month. (Female GRP 3_Vill 3)

Vignette 1: Consequences of child/early marriage, and awareness-building

Sahana Begum's eldest daughter was married at the age of 14 . Sahana was very happy at that time, thinking that her daughter would have a healthy and peaceful conjugal life. After a year her daughter was pregnant. During her pregnancy, the daughter felt pain in her abdomen; but Sahana ignored it and dismissed her daughter claims, believing it to be a problem for all pregnant women. Instead of going to the doctor, they waited for celebrating the moment of birth. But when the situation became worse, they did visit to the doctor; they found that there were complications in the pregnancy, and that the life of either mother or son was at risk. Sahana became confused and kept praying for both lives to be saved. The doctor saved her daughter's life. Later Sahana learned from Gonokendra multimedia sessions that marrying too early can causes birth complications leading to the mother's death. Since then she is aware of the problem: she did not make her other two daughters get married before the age of 18. (Female GRP 6_Vill 2)

So Gonokendra multimedia sessions have played a role in stopping child marriage; for our participants told us they had been made aware of the negative effects of from the practice through their Gonokendras. To prevent or delay young girls' marriages, guardians are sending their daughters or sisters to schools, colleges or universities, a practice previously very rare. On some occasions, people who have attended Gonokendra inspire others to stop child marriages. Vignette 2 presents an illustration demonstrating how a rural carpenter motivated others through the knowledge he acquired from Gonokendra multimedia session.
Vignette 2: Stopping early marriage

When Nasima was only 14, her father, an illiterate farmer, was about to force her to marry a 27-year-old man; but Md. Anwar, 32, a carpenter by profession and brother-in-law of Nasima's father, put a stop to this early marriage. He was a semi-literate carpenter, and aware of the unlawfulness of the practice and of its dire consequences through the Gonokendra multimedia programs. Though Nasima's brothers and sister were educated, they didn't raise their voices against their father's decision, for they were financially dependent on him. But Md. Anwar did a noble job by calling the police immediately, despite the possibility of breaking the good relationship with his brother-in-law. The early marriage was stopped and Md. Anwar saved a teenager's life from the possibly devastating consequences. (Male GRP 7_Vill 2)

Though most of the participants understand the importance of preventing child marriage, the practice has not completely disappeared from their society. Some of them were witnesses of child marriage and the incidence of complications during childbirth due to the youth of the pregnant girl. They told us that girls' families became anxious for them to get married, rather than to continue their education, as soon as they leave adolescence. And this can be seen in our three Gonokendra villages - many girls leaving school or college.

\subsection{Prohibition of Dowry}

Usually the rich give a dowry as a blessing or a gift, but the poor cannot afford it. However, they are forced to give one. (Male FGD 5_Vill 3)

Another issue disseminated through Gonokendra multimedia sessions is dowry, where the bride's family gives valuable gifts of cash or assets to the groom's family at the marriage, is considered by the Bangladesh government to be a social curse. ${ }^{5}$ Marriage is almost universal in Bangladesh: afterwards, a woman moves from her natal home to her husband's, shifting her dependence accordingly. ${ }^{6,18}$ Dowry is paid before, after or during the marriage ceremony; and delaying a dowry payment incurs abuse of the bride or the bride's family. ${ }^{19}$ Dowry is deeply rooted in the patriarchal society of Bangladesh and its influence has caused misery to many, often with painful consequences for the bride’s family. 
Research indicates that dowry is a crucial issue sparking the range of violence against women in Bangladesh - there are also rape, trafficking, acidthrowing, divorce, child marriage and polygamy. ${ }^{20,21}$ Because of dowries, women have been killed and many victimised by physical and mental abuse. According to Odhikhar, an NGO in Bangladesh, of 1,683 women who were victims of dowry-related violence, 1,088 women had been killed and of the others, 440 had endured torture, during 2002-2006.

While the increase in dowry transactions was generally viewed as a negative social change, several participants still hold the view that dowry is helpful, in that it ensures the bride's being well-respected when joining the marital household. As one participant suggests,

Unfortunately, dowry has become an indispensable part of marriage, for rich or poor. We either give a dowry to a groom's father or our daughter never gets married. (FGD Female 4_Vill 1)

As a consequence of arranging dowry payment, the bride's family is often left in extreme hardship. How the practice is pervading rural society is powerfully illustrated by the miserable story of one housewife:

One day I went to my aunt's neighbour's house and heard that Kurula, 18-year-old married daughter of that house, was sent back to her natal home because Kurula's father was unable to pay dowry to her in-laws. Kurula was very frustrated, but also frightened to go back to her husband. Her husband said that she could not stay with him unless her father fulfilled the dowry promise of their marriage ceremony. Kurula's father was very poor and it was difficult for him to arrange such a large amount; so he made up his mind to sell his remaining lands for the happiness of his beloved daughter. (Female Trainee 5_Vill 1)

Some serious consequences arise when the promised dowry is not paid in full. And even when it is, the safety of the bride is not assured. Dowry issues can lead to domestic violence - to beatings, threats of murder and divorce. A housewife says:

We have no option to giving a dowry; if we don't, husbands will beat us or abandon us to our natal home. To prevent this, we do all the housework and we remain in silence if they get married again. (Female Guardian 3_Vill 2)

When we talked with our participants about the pernicious effects of dowry and asked what they can do about it, they replied that the practice has reduced to some extent but while it remains desirable by some, it cannot be removed. We found that the majority of our respondents were aware about the unlawfulness of it, but the law is difficult to apply when traditional social norms and beliefs have been exercised for many years. A trainee states:

We know that dowry is illegal and that the consequences can be family violence, but it is not possible to stop practising it as our society has already accepted it. And we cannot keep our girls in the home for a long time without marriage. Therefore, we do not have any option but to make dowry payments for the sake of our daughters' lives. (Female Trainee 4_Vill 1) While it would be expected that educated men and women would not be interested in dowry, our field data reveals a completely different picture, where an educated woman's parents are forced to pay a higher dowry for a compatible groom. As one rural person states:

If our daughter is educated then things are more critical: we have to find an educated husband difficult in our village where the majority of people are illiterate. If we find one his family demands a big dowry from us. (Male GRP 2_Vill3)

Unfortunately, dowry has become an indispensable part of marriage, for rich or poor. We either give a dowry to a groom's father or our daughter never gets married. (FGD Female 4_Vill 1)

However, a male participant puts a quite different view: Job scarcity is a major problem in village areas. A number of we graduates remain unemployed here, and we don't have capital to set up our own businesses. Girls' fathers use that opportunity and offer us cash or assets to marry their girls, who are mostly illiterate. (Male Trainee 2_Vill 1)

From the above field data, it is seen that the practice of dowry is still widespread in Gonokendra villages, despite participants' awareness that it is unlawful and has dire consequences. It is the existing social system, a social custom; and the primitive mind-set of the villagers accepts the practice in their male-dominated society. A female guardian, for instance, does not hesitate to take and give dowry: 'Dowry will help the financial wellbeing of my son (Female FGD 5_Vill 1)'.

One group of participants considers:

It's a controversial issue: some are giving money willingly to their son-in-law, but some only by force. 
People treat this issue in different ways. I gave dowry willingly during my daughter's marriage. (Male GRP 9 _ Vill 2)

In our research we can't see a resolution of the issue of dowry. From the general discussion, it is clear that Gonokendra multimedia sessions play a role in informing and awakening people about the consequences and the legal aspects of dowry. Our participants feel that dowry is the consequence of poverty and social custom, and it needs to be addressed in their society in terms of strictly enforcing the law that forbids it.

\subsection{Seeking Legal Support from the Court, rather than in Salish}

As rich, influential people in our village manipulate the verdicts of salish, we now go to the formal legal court when seeking legal help. (Male Trainee 3_ Vill 3)

Salish has been looked on almost like pre-trial — it is expected to get a good negotiation among parties or effect a compromise between them. It has a long history, and villagers usually seek assistance from salish for resolving issues related to family affairs, though it has little legal backing. ${ }^{22}$ Most often poor village members complain that proper justice is denied there, as it has been controlled by the influential rich and the politicians. ${ }^{6} \quad$ Mostly, supplicants who have good connections with these get favourable judgments. For instance, a woman at marriage is promised a commitment — mehr (cash or assets) — from her husband; and if divorce occurs the mehr must be paid to her, according to Bangladeshi Islamic law. Unfortunately, many women are deprived of this: our participants say that in several divorces which were 'ratified' through salish, the question of paying the mehr seldom arose.

To address this challenge, Gonokendra multimedia sessions are continuously making people aware of existing laws on legal and human rights, and encouraging them to seek assistance from a formal court rather than in salish; and of motivating people to raise their voices against the injustices of salish. Our field data demonstrate that participants from our three villages have grown conscious of many legal issues (divorce law, human rights, etc.) and now take to the courts for legal assistance. They realise that the salish system takes advantage of their ignorance regarding different legal aspects; and that it has imposed injustice upon them on many occasions. However, the situation is changing since rural people have been involved with Gonokendra; we cite a classic example:

A poor housewife came to a Gonokendra's librarian/trainer complaining that her husband beat her regularly; though she intended to make the complaint in salish, she knew that it wouldn't succeed without good connections with influential people in her village. As soon as she understood the legal aspects of women's and children's rights from her Gonokendra's multimedia sessions, she decided to seek assistance from the legal court rather than from salish. The Gonokendra's librarian/trainer also advised her about the court procedure. Later, the court called in the plaintiff's husband and proper justice was done. (Trainer_Vill 3)

\section{Conclusion}

Access to Information Technology (IT) is argued to be an effective way to narrow the gap between the rich and the poor; between rural and urban populations; and between being isolated in a poor village with very little access to the outside world and being able to participate in an increasingly technological global village. ${ }^{23}$ In short, an ICT intervention can bridge the digital-divide. The World Bank ${ }^{24}$ concurs: "This new technology greatly facilitates the acquisition of knowledge, offering developing countries unprecedented opportunities to enhance educational systems.... and widen the range of opportunities for business and the poor.”

In such a developing country like Bangladesh, it is currently economically impossible to link individual households' level, but work has commenced at the community level through IT. $^{25,26}$ By addressing the challenge of providing access to basic legal information, Gonokendra has been actively responding the challenges of the digital-divide. The findings of this research show that the IT programs offered by this Gonokendra are highly regarded by the villagers, who are positive towards the Gonokendra and the outcomes. However, applying their learning or knowledge in the real word is not straight forward due to many factors like traditional beliefs and practices (e.g., gender discrimination attitudes of the society). However, through the various participants' perceptions, attitudes and experiences, it is clear that this particular Gonokendra is providing access to technology (computers), promoting computer literacy, and empowering community-based committees to deliver a 
comprehensive range of educational and social support activities in its village. In near future, all the public services including judiciary and land procurement; is about to come under the umbrella of information and communication technology. In that sense the rural people cannot step backward from them, someone has to come forward, and Gonokendra is exactly the very thing.

\section{References}

1. Mintoo, A. A. (2004). Bangladesh: Anatomy of Change. Dhaka, Bangladesh, The University Press Limited.

2. BBS (2011). Bangladesh Bureau of Statistics, National Economic Review 2011, Dhaka.

3. BRAC (2004). BRAC annual report: 2004. Dhaka, Bangladesh.

4. Ghimire K. B. (2003). Land reform and peasant livelihoods, ITDG Publishing, London

5. Khan, M. K. A. (2000). Assessing operational status of BRAC Gonokendra Pathagars. BRAC. 75 Mohakhali, Dhaka1212, Bangladesh: 326-352.

6. Khan, M. K. A. and S. Akter (1999). An analysis of issues and problems of BRAC's Gonokendra Pathagars. BRAC. 75 Mohakhali, Dhaka-1212, Bangladesh: 134-160.

7. BRAC (2003). BRAC Project proposal: 2004-2009. B. e. program. Dhaka, Bangladesh., Bangladesh Rural Advancement Committee (BRAC).

8. Chowdhury, J. (2002). Promotion of IT in the rural communities of Bangladesh: Experiences of BRAC, Center for Mass Education in Science(CMES) and Grameen Communication. Dhaka, Bangladesh: 39.

9. Myers, M. D., \& Avison, D. (2002). An introduction to qualitative research in information systems. Qualitative research in information systems, 4, 3-12.

10. Walsham, G., \& Sahay, S. (2006). Research on information systems in developing countries: Current landscape and future prospects. Information Technology for Development, 12(1), 7-24.

11. Taylor, S., \& Bogdan, R. (1984). Introduction to research methods. New York: Wiley.

12. Myers, M. D., \& Avison, D. (1997). Qualitative research in information systems. Management Information Systems Quarterly, 21, 241-242.
13. Boyatzis, R. E. (1998). Transforming qualitative information: Thematic analysis and code development. Sage Publications

14. Miles, M. B., \& Huberman, A. M. (1994). Qualitative data analysis: An expanded sourcebook, Sage Publications.

15. Stake, R. (1995). The art of case research. Newbury Park, CA: Sage Publications.

16. Benbasat, I., Goldstein, D. K., \& Mead, M. (1987). The case research strategy in studies of information systems. MIS quarterly, 369-386.

17. Klein, H. K., \& Myers, M. D. (1999). A set of principles for conducting and evaluating interpretive field studies in information systems. MIS quarterly, 67-93.

18. Bhuiya, A., \& Chowdhury, M. (1997). The effect of divorce on child survival in a rural area of Bangladesh. Population Studies, 51(1), 57-61.

19. Chowdhury, F. D. (2010). Dowry, women, and law in Bangladesh. International Journal of Law, Policy and the Family, 24(2), 198-221.

20. Huda, S. (2006). Dowry in Bangladesh: Compromizing women’s rights. South Asia Research, 26(3), 249-268.

21. Masud Ahmed, S., Chowdhury, M., \& Bhuiya, A. (2001). Micro-credit and emotional well-being: experience of poor rural women from Matlab, Bangladesh. World Development, 29(11), 1957-1966.

22. Rafi, M., Banu, D., Alim, M. A., \& Akter, S. (2003). An Assessment of Male Attitude Towards Violence Against Women.

23. PACE (2005). ICT in Multi-purpose community learing centres/Gonokendras. Brief on IT. BRAC. Dhaka, Bangladesh, Bangladesh Rural Advancement Committee (BRAC)

24. World Bank (1998).World Development Report. Washington, DC: World Bank

25. Mansell, R. and U. Wehn (1998). Knowledge societies : information technology for sustainable development. Oxford; New York, Published for and on behalf of the United Nations by Oxford University Press.

26. Bank, W. (1998). World Development Report. Washington, DC. 